\title{
A new capacitance medium for presumptive detection of Listeria spp. from cheese samples
}

\author{
Maria José R.M. Rodrigues, Christopher J. Capell*, Roy M. Kirby \\ Escola Superior de Biotecnologia, Rua Doutor António Bernardino de Almeida, 4200 Porto, \\ Portugal
}

\begin{abstract}
The paper presents a new medium and a method for the rapid presumptive detection of Listeria spp. in cheese samples by electrical capacitance changes. The Bactometer based capacitance broth (LED medium) required a $30 \%$ change in signal within $30 \mathrm{~h}$ to identify presumptive positive results. Of 32 cheese samples tested, 10 were found to contain Listeria spp. using a Fraser broth screening method and 12 using the LED medium and method. The LED method also gave 16 fewer (total $=1$ ) false presumptive positive results. Results show the LED method to be superior to Fraser broth in regard to both the number of false presumptive positive and confirmed false negative results detected. The method appears to be suitable as a reliable rapid screen for the presence of Listeria spp. in cheese.

Keywords: Bactometer; Electrical detection; Listeria; Portuguese cheese; Presumptive media
\end{abstract}

\section{Introduction}

Cheeses, especially soft varieties, are closely associated with food-borne listeriosis outbreaks both in Europe and North America [1-3]. Pasteurization effectively eliminates the bacterium and most cheeses possess a $\mathrm{pH}$ that inhibits Listeria monocytogenes growth. Due to infection during manufacturing, microenvironments in and around the product, poor handling and distribution or a combination of these, higher $\mathrm{pH}$ cheeses may become high inoculum sources of the bacterium. Cheese is also associated with other bacterial genera capable of giving false positive results in Listeria media, most notably Bacillus spp. and Enterococcus spp. [4].

* Corresponding author. Tel: +351-2-5580045; fax: +351-2-5580063; e-mail: chris@esb.ucp.pt. 
Rapid detection or enumeration of $L$. monocytogenes in food samples is difficult as it grows quite slowly on selective media, is usually present in quite low numbers and damaged cells may be inhibited by selective agents $[2,5]$.

Much has been published on the application of new immunological and genetic technologies, for instance polymerase chain reaction $[6,7]$, gene-probe $[8,9]$, and ELISA [10] for detecting Listeria spp. or L. monocytogenes. These tests are successful in reducing the detection or confirmation time but are generally expensive in reagents, and most require an enrichment to be performed.

The balance between relevance, accuracy, time and cost of microbiological screening has to be attained within a food company's quality programme, with time and cost usually given greatest priority. For this reason improvements in the standard F.D.A. and U.S.D.A.-F.S.I.S. methods [11], which are slow, are required.

Fraser broth [12] is widely used as an alternative to UVM 2 in the U.S.D.A.F.S.I.S. method; it is the first stage at which negative results may be rejected and it is known to be a good Listeria spp. cultural medium. Fraser broth has problems with large numbers of false presumptive positive results [12-14]. Any possibly false positive cultures have to be allowed at least 2 days on agar before they are rejected as negative, or, if alternative rapid confirmation techniques are used on the broth cultures, expensive test kits are wasted.

Initial work on the application of the Bactometer to Listeria spp. isolation from artificially inoculated food samples [15] resulted in the use of Oxford agar antibiotic supplements in a liquid medium. This medium allowed the detection of Listeria spp. by the observation of greater than $30 \%$ change in capacitance within $30 \mathrm{~h}$ when inoculated from UVM 1 primary enrichment broths. The objective of the current work was to test that the medium and method was able to identify naturally contaminated cheese samples.

\section{Materials and methods}

\subsection{Primary enrichment}

Samples of four varieties of cheese (very soft, Queijo Fresco; soft, Camembert and Queijo Serra das Estrelas; and semi-soft, Queijo Flamengo) were bought in a range of retail outlets and refrigerated before use. $25 \mathrm{~g}$ samples were taken aseptically and homogenized in $225 \mathrm{ml}$ of UVM 1 (Oxoid) in a stomacher (Seward 400) for $2 \mathrm{~min}$. These primary selective enrichment broths were incubated at $30^{\circ} \mathrm{C}$ for $24 \mathrm{~h}$ before secondary differential enrichment.

\subsection{Secondary enrichment}

Listeria Electrical Detection medium (LED) was made from a base of $20 \mathrm{~g} \mathrm{l}^{-1}$ of tryptone (Oxoid), $20 \mathrm{~g} \mathrm{l}^{-1}$ of yeast extract (Oxoid), $17.5 \mathrm{~g} \mathrm{l}^{-1}$ lithium chloride (Oxoid), $4 \mathrm{~g} \mathrm{l}^{-1}$ glucose (BDH) and $1 \mathrm{~g} \mathrm{l}^{-1}$ esculin (Sigma). After sterilization of 
the base 4 vials $~^{-1}$ of Oxford Selective Supplements (Oxoid) and $20 \mathrm{mg}^{-1}$ of a nalidixic acid (Sigma) filter sterilized stock solution were added. The $\mathrm{pH}$ was then aseptically adjusted to $7.2 \pm 0.1$.

A Vitec-Bactometer (Model M64, BioMèrieux) was used to monitor capacitance during the test. $0.05 \mathrm{ml}$ of each primary selective enrichment were added to $2 \mathrm{ml}$ of the LED medium that had been prewarmed to $30^{\circ} \mathrm{C}$ in the Bactometer module wells; all tests were replicated at this stage. The Vitec-Bactometer was set to monitor capacitance for a test time of $40 \mathrm{~h}$ at $30^{\circ} \mathrm{C}$. Positive results were taken as those that gave greater than $30 \%$ change in capacitance within $30 \mathrm{~h}$. All wells were streaked onto Oxford agar (Oxoid) after the test and incubated $\left(30^{\circ} \mathrm{C}, 48\right.$ h).

At the same time $0.1 \mathrm{ml}$ of primary selective enrichment medium was transferred to $10 \mathrm{ml}$ of Fraser broth [12] and incubated $\left(30^{\circ} \mathrm{C}, 48 \mathrm{~h}\right)$. Fraser results (blackening) were noted after $24 \mathrm{~h}$ and $48 \mathrm{~h}$. All enrichment samples of were streaked onto Oxford agar (Oxoid) and incubated $\left(30^{\circ} \mathrm{C}, 48 \mathrm{~h}\right)$.

\subsection{Confirmation}

Confirmation was performed to the genus level by first producing a pure sub-culture of Oxford typical colonies onto tryptone soy agar $\left(\mathrm{TSA}, 37^{\circ} \mathrm{C}, 24 \mathrm{~h}\right.$ ) (Oxoid), noting: the appearance by Henrys' illumination, catalase and oxidase reaction from the TSA plate and tumbling motility from tryptone soy broth ((Lab $\mathrm{M}), 22^{\circ} \mathrm{C}, 24 \mathrm{~h}$ ) inoculated from the TSA plate. Further confirmation by filtersterilised sugar fermentation tests of D-raffinose $(0.5 \%(\mathrm{w} / \mathrm{v}))$ and sorbitol, D-arabitol, xylitol and trehalose (all 0.75\% (w/v)) (all from Sigma) in Purple broth (Difco) were used to add certainty of identification for up to five typical colonies per Oxford agar plate (where available). Purple broths were incubated at $30^{\circ} \mathrm{C}$ for 5-7 days. API Listeria (BioMérieux) biochemical tests were performed on all isolates that gave typical looking colonies on Oxford agar but atypical results for any of the following tests and on some typical isolates.

Finally, all confirmed Listeria spp. isolates were inoculated back into UVM 1, incubated $\left(30^{\circ} \mathrm{C}, 24 \mathrm{~h}\right)$ and transferred to LED medium (0.05 ml UVM 1 into 2 $\mathrm{ml}$ LED) in the Bactometer to ensure that each produced $>30 \%$ change in capacitance within $30 \mathrm{~h}$ at $30^{\circ} \mathrm{C}$.

\section{Results}

The complete confirmation procedure of the U.S.D.A.-F.S.I.S. L. monocytogenes method was not followed due to the problems of obtaining sheep and horse blood for Camp and Columbia blood agar locally; the final reports are only of Listeria spp. except where API Listeria tests were performed. The additional sugar fermentation tests were used to reduce the possibility of error in the Listeria spp. identification. All isolates identified as Listeria spp. were oxidase negative, catalase positive, Gram positive rods, exhibiting tumbling motility, Henry 
illumination positive, sorbitol and D-raffinose negative and D-arabitol, xylitol and trehalose positive in Purple broth fermentations. The sugar fermentation results all agreed with the API Listeria results and seemed an accurate but slow method of confirmation of Listeria spp.

The two positive results confirmed from the LED medium method but not the Fraser broth method were re-streaked from Fraser broth onto Oxford agar after $48 \mathrm{~h}$, but still did not give typical colonies.

All Listeria sp. isolates when re-inoculated into the Bactometer in pure culture from UVM 1 gave $>30 \%$ change in capacitance within $30 \mathrm{~h}$.

\section{Discussion}

In preliminary experiments using local cheeses known to contain Listeria spp. (results not shown) difficulties with interpretation of capacitance curves due to variable initial values of capacitance led to problems in confirmation of the presence of the bacteria. Ferric ammonium citrate was removed from the previously reported medium to make LED medium as the observation of the esculin reaction had been found to be unnecessary, subsequent experiments showed much improved results (Table 1). It was therefore concluded that in this case ferric ammonium citrate was detrimental to the efficiency of the medium.

The LED medium tests were performed in duplicate in order to balance the volumes of UVM I transferred and to indicate the internal variation of the Bactometer. These duplicates gave two confirmed positive results that spanned the $30 \%$ change in $30 \mathrm{~h}$ cut-off. This intra-sample variation may have been due to competitive inhibition of Listeria spp. growth in the medium, very low initial numbers and poor distribution of bacteria in the primary enrichment or poor technique. The particle size and the adhesive nature of some cheeses make accurate transfer of small volumes difficult. Discounting the two tests spanning $30 \% / 30 \mathrm{~h}$ the average intra-sample variation of time to reach $30 \%$ change in capacitance was small $(0.5 \mathrm{~h})$ and showed a large range $(2-29 \mathrm{~h})$.

The LED method gave a greater number of confirmed Listeria spp. positive results $(12 / 32)$ than the Fraser broth method (10/32). For two samples confirmed as Listeria spp. positive by the LED method Listeria spp. colonies were not isolated on Oxford agar plates from positive Fraser broths; it was noted that the corresponding isolates from LED medium gave comparatively weak catalase reactions. The LED method also gave far fewer false presumptive positive results (1/32) than the Fraser broth method (19/32). The 65.5\% false presumptive positive rate for Fraser broth is within the range reported for other products by other authors $[12-14,16]$. The number of confirmed positive samples from each cheese type was inversely proportional to the hardness of the cheese; however the number of false presumptive positive results from Fraser broth was not. This may indicate that other esculin hydrolysing organisms capable of growing in Fraser broth are not as sensitive as Listeria spp. to the preservative effects of harder cheeses. 
Table 1

Presumptive and confirmed results of 32 cheese samples tested for Listeria spp.

\begin{tabular}{|c|c|c|c|c|c|c|}
\hline \multicolumn{2}{|c|}{$\begin{array}{l}\text { Cheese } \\
\text { sample }\end{array}$} & $\begin{array}{l}\text { Times to } 30 \% \\
\text { change (h) }\end{array}$ & $\begin{array}{l}\text { Bactometer } \\
\text { presumptive }\end{array}$ & $\begin{array}{l}\text { Confirmed } \\
\text { Listeria spp. }\end{array}$ & $\begin{array}{l}\text { Fraser broth } \\
\text { presumptive }\end{array}$ & $\begin{array}{l}\text { Confirmed } \\
\text { Listeria spp." }\end{array}$ \\
\hline \multirow[t]{8}{*}{ Fr } & & $23 / 34$ & $+1-$ & + & + & + \\
\hline & 2 & $4 / 4$ & $+1+$ & + & + & + \\
\hline & 3 & $23 / 23$ & $+1+$ & + & + & + \\
\hline & 4 & $20 / 34$ & $+1-$ & -1 & + & - \\
\hline & 5 & $14 / 14$ & $+1+$ & $t^{e}$ & + & + \\
\hline & 6 & $17 / 17$ & $+1+$ & $t^{d}$ & + & + \\
\hline & 7 & $2 / 2$ & $+1+$ & + & + & $-{ }^{f}$ \\
\hline & 8 & $2 / 2$ & $+1+$ & + & + & + \\
\hline \multirow[t]{8}{*}{ Ca } & a 1 & $-1-$ & $-1-$ & - & + & - \\
\hline & 2 & $28 / 36$ & $+1-$ & + & + & + \\
\hline & 3 & $-1-$ & $-1-$ & - & + & - \\
\hline & 4 & $40 /-$ & $-1-$ & - & - & - \\
\hline & 5 & $26 / 29$ & $+1+$ & + & + & - \\
\hline & 6 & $11 / 10$ & $+1+$ & $+^{c}$ & + & + \\
\hline & 7 & $-1-$ & $-1-$ & - & + & - \\
\hline & 8 & $-1-$ & $-1-$ & - & 1 & $f$ \\
\hline \multirow[t]{8}{*}{ Se } & 1 & $17 / 17$ & $+1+$ & $+^{c}$ & + & + \\
\hline & 2 & $-1-$ & $-1-$ & - & + & - \\
\hline & 3 & $-1-$ & $-1-$ & - & + & - \\
\hline & 4 & $16 / 17$ & $+1+$ & $t^{c}$ & + & + \\
\hline & 5 & $-1-$ & $-1-$ & - & + & - \\
\hline & 6 & $-1-$ & $-1-$ & - & + & - \\
\hline & 7 & $-1-$ & $-1-$ & - & - & - \\
\hline & 8 & $-1-$ & $-1-$ & - & - & - \\
\hline \multirow[t]{8}{*}{ FI } & 1 & $-1-$ & $-1-$ & - & + & - \\
\hline & 2 & $-1-$ & $-1-$ & - & + & - \\
\hline & 3 & $-1-$ & $-1-$ & - & + & - \\
\hline & 4 & $-1-$ & $-1-$ & - & + & - \\
\hline & 5 & $-1-$ & $-1-$ & - & + & - \\
\hline & 6 & $-1-$ & $-1-$ & - & + & - \\
\hline & 7 & $-1-$ & $-1-$ & - & + & - \\
\hline & 8 & $-1-$ & $-1-$ & - & + & - \\
\hline
\end{tabular}

${ }^{a}$ Cheese Types: Fr; Queijo Fresco, Ca; Camembert, Se; Queijo Serra das Estrelas, Fl; Queijo Flamengo.

${ }^{\circ}$ API Listeria Biochemical Results: ${ }^{\circ}:$ L. monocytogenes, ${ }^{\mathrm{d}}:$ L. innocua, ${ }^{\mathrm{C}}:$ L. seeligeri, ${ }^{\mathrm{f}}:$ Not a Listeria spp.

The results suggest that by using the LED method the number of presumptive positive samples requiring confirmation at the end of sccondary enrichment could be substantially reduced. This would lead to saving of time and reagents in the confirmation phase of the analysis. The reduction in false presumptive positives is achieved without increasing the number of false negative results. Furthermore the low numbers of false positive results $(3.1 \%)$ suggest that the Bactometer method may be employed as a rapid screen as part of a company's internal G.M.P. programme. 


\section{Acknowledgments}

M.J.R.M.R. was funded by Grant BM/2063/91/IF from the Junta Nacional de Investigação Cientifica e Tecnologica, Lisboa, Portugal.

\section{References}

[1] Farber, J.M. and Peterkin, P.I. (1991) Listeria monocytogenes, a food-borne pathogen. Microbiol. Rev. 55, 476-511.

[2] Prentice, G.A. and Neaves. P. (1988) Listeria monocytogenes in food: its significance and methods for its detection. Bull. Int. Dairy Fed. 223/1988.

[3] $M^{C}$ Lauchlin, J. (1987) Listeria monocytogenes, recent advances in the taxonomy and epidemiology of listeriosis in humans. J. Appl. Bacteriol. 63, 1-11.

[4] Curtis, G.D.W., Mitchell, R.G., King, A.F. and Griffin, E.J. (1989) A selective differential medium for the isolation of Listeria monocytogenes. Lett. Appl. Microbiol. 8, 95-99.

[5] Lovett. J (1988) Isolation and enumeration of Listeria monocytogenes. J. Food Technol. 42. $172-175$.

[6] Fitter, S.. Heuzenroeder. M. and Thomas. C.J. (1992) A combined PCR and selective enrichment method for rapid detection of Listeria monocytogenes. J. Appl. Bacteriol. 73, 53-59.

[7] Fluit, A.C. Torensma, R., Visser, M.J.C., Aarsman, C.J.M., Poppelier. M.J.J.G., Keller, B.H.I., Klapwijk, P. and Verhoef, J. (1993) Detection of Listeria monocytogenes in cheese with the magnetic immuno-polymerase chain reaction assay. Appl. Environ. Microbiol. 59, 12891293.

[8] Niederhauser, C. Hofelein, C., Luthy, J., Kaufmann, U., Buhler. H.P. and Candrian, U. (1993) Comparison of Gen-Probe DNA Probe and PCR for detection of Listeria monocytogenes in naturally contaminated soft cheese and semi-soft cheese. Res. Microbiol. 144, 47-54.

[9] Wang, R.F.. Cao, W.W. and Johnson, M.G. (1992) 16S rRNA-based probes and polymerase chain reaction method to detect Listeria monocytogenes cells added to foods. Appl. Environ. Microbiol. 58, 2827-2831.

[10] Walker, S.J., Archer, P. and Appleyard, J. (1990) Comparison of the Listeria-Tek ELISA kit with cultural procedures for the detection of Listeria species in foods. Food Microbiol. 7 . $335-342$.

[11] Pusch. D.J. (1989) A review of current methods used in the United States for isolating Listeria from food. Int. J. Food Microbiol. 8. 197-204.

[12] Fraser, J.A. and Sperber, W.H. (1988) Rapid detection of Listeria spp. in food and environmental samples by esculin hydrolysis. J. Food Prot. 51, 762-765.

[13] Warburton, D.W., Farber, J.M., Armstrong, A., Caldeira, R., Tiwari, N.P., Babiuk, T., Lacasse, P. and Read, S. (1991a) A Canadian comparative study of modified versions of the 'FDA' and 'USDA' methods for the detection of Listeria monocytogenes. J. Food Prot. 54, 669-676.

[14] Warburton. D.W., Farber, J.M., Armstrong, A., Caldeira, R., Hunt, T., Messier. S., Plante, R., Tiwari. N.P. and Vinet, J. (1991b) A comparative study of the 'FDA' and 'USDA' methods for the detection of Listeria monocytogenes. Int. J. Food Microbiol. 13, 105-118.

[15] Capell, C.J.. Kirby, R.M. and Moss, M.O. (1995) A method and medium for the electrical detection of Listeria spp. from food. Int. J. Food Microbiol. 25, 169-177.

[16] Lund, A.M., Zottola, E.A. and Pusch. D.J. (1991) Comparison of methods for isolation of Listeria from raw milk. J. Food Prot. 54, 602-606. 